\title{
Correction: A comparison of statistical methods for the detection of hepatocellular carcinoma based on serum biomarkers and clinical variables
}

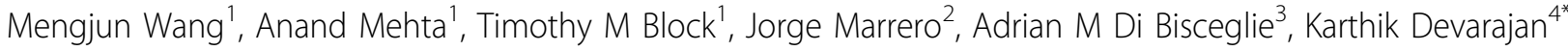

From IEEE International Conference on Bioinformatics and Biomedicine 2012

Philadelphia, PA, USA. 4-7 October 2012

\section{Correction}

Our original article was published in BMC Medical Genomics in the supplement containing selected articles from the IEEE International Conference on Bioinformatics and Biomedicine 2012 (IEEE BIBM 2012) [1]. After publication,

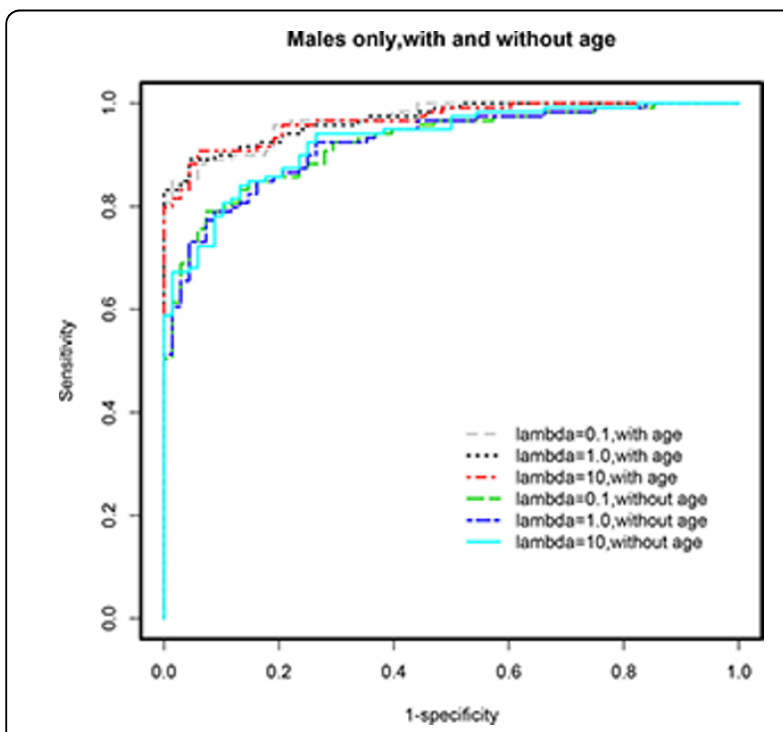

Figure 1 ROC curves based on multivariable stepwise penalized logistic regression models (stepPLR) using the stratified maleonly subset. The age-adjusted final model for $\lambda=0.1$ showed the best performance in terms of AUC. A clear distinction is seen in the ROC curves for age-adjusted models compared to age-unadjusted models. Age-adjusted models demonstrated superior performance overall across all choices of $\lambda$. See Table 1 for detailed results and the text for discussion of these results.

${ }^{4}$ Department of Biostatistics and Bioinformatics, Fox Chase Cancer Center, 333 Cottman Avenue, Philadelphia, PA 18901, USA

Full list of author information is available at the end of the article it was noticed that the ROC curves in Figures 1, 2, 3, 4 displayed Sensitivity vs. Specificity rather than Sensitivity vs. 1-Specificity, as labeled. These figures have been reproduced here in the correct format, displaying Sensitivity vs. 1-Specificity, and should replace the corresponding figures in the original article. However, AUC values remain unaffected by this change.

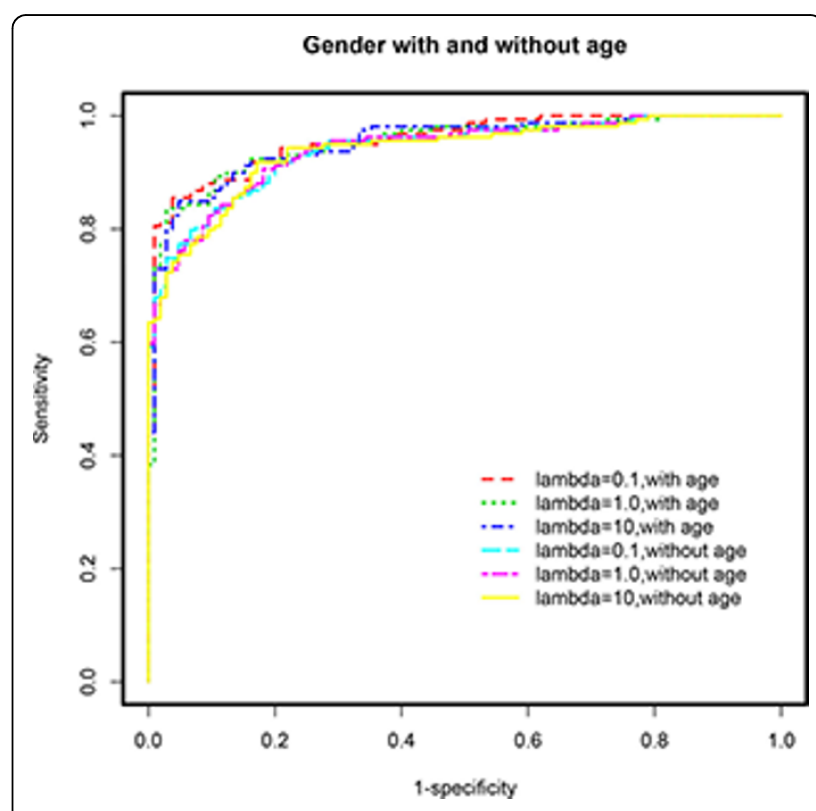

Figure 2 ROC curves based on multivariable stepwise penalized logistic regression models (stepPLR) adjusting for gender effect. Models that are also adjusted for age effect outperformed those that did not control for age, across all choices of the parameter $\lambda$. The age-adjusted final model for $\lambda=0.1$ showed the best performance in terms of AUC. See Table 1 for detailed results and the text for discussion of these results. 


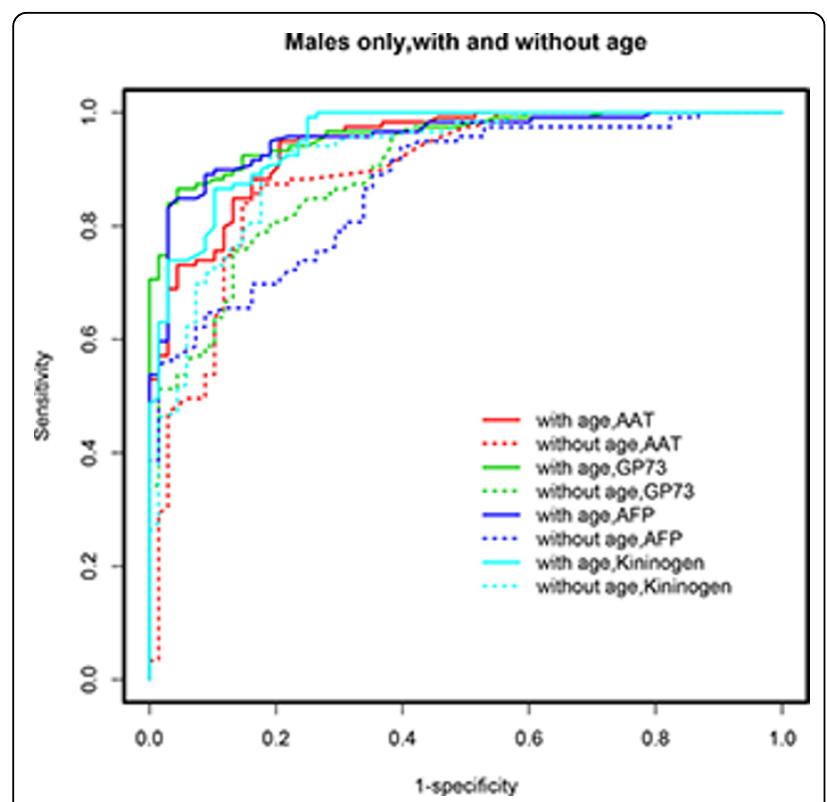

Figure 3 ROC curves based on multivariable model-based CART analyses $(\mathrm{mob})$ using the stratified male-only subset. Age-adjusted models demonstrated superior performance in terms of AUC. A clear distinction is seen in the ROC curves for age-adjusted models (solid lines) compared to age-unadjusted models (dotted lines). See Table 1 for detailed results and the text for discussion of these results.

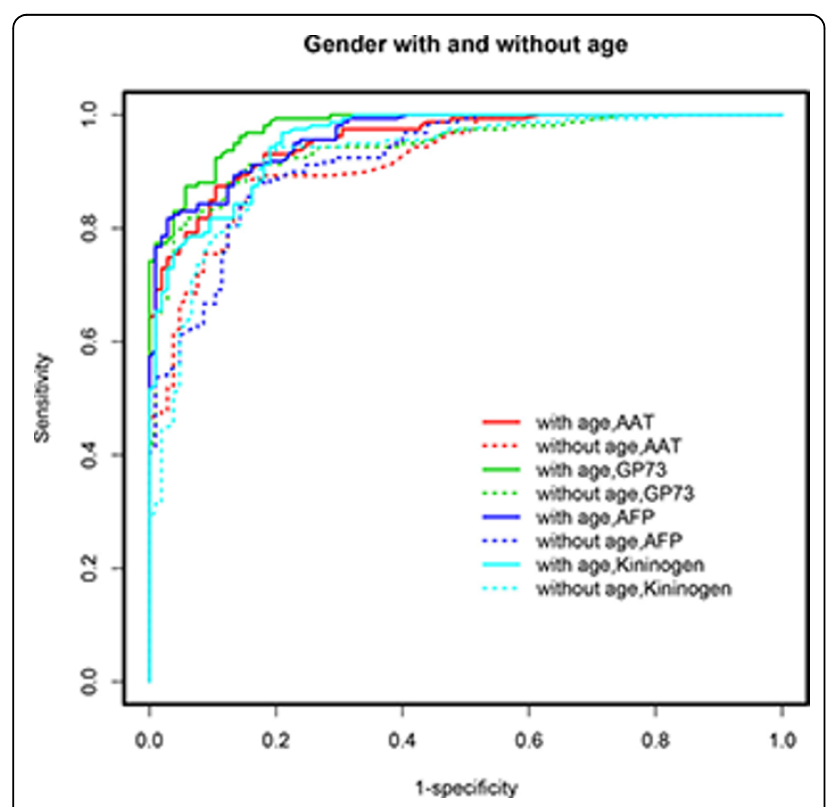

Figure 4 ROC curves based on multivariable model-based CART analyses (mob) incorporating gender and/or age. Age-adjusted models demonstrated superior performance in terms of AUC when gender effect is accounted for in each model. A clear distinction is seen in the ROC curves for age-adjusted models (solid lines) compared to age-unadjusted models (dotted lines). Table 1 lists the performance measures for these models. A detailed discussion of the results is provided in the text.

\section{Acknowledgements}

This article has been published as part of BMC Medical Genomics Volume 6 Supplement 3, 2013: Selected articles from the IEEE International Conference on Bioinformatics and Biomedicine 2012: Medical Genomics. The full contents of the supplement are available online at http://www. biomedcentral.com/bmcmedgenomics/supplements/6/S3.

\section{Authors' details}

'Drexel University College of Medicine, 3508 Old Easton Rd, Doylestown, PA 18902, USA. ${ }^{2}$ Division of Gastroenterology, University of Michigan, 3912 Taubman Center, Ann Arbor, Ml 48109, USA. ${ }^{3}$ Saint Louis University School of Medicine, 1402 S. Grand FDT 12th Floor, St. Louis, MO 63104, USA. ${ }^{4}$ Department of Biostatistics and Bioinformatics, Fox Chase Cancer Center, 333 Cottman Avenue, Philadelphia, PA 18901, USA.

Published: 20 December 2013

\section{Reference}

1. Wang M, Mehta A, Block TM, Marrero J, Di Bisceglie AM, Devarajan K: A comparison of statistical methods for the detection of hepatocellular carcinoma based on serum biomarkers and clinical variables. BMC Medical Genomics 2013, 6(Suppl 3):S9.

doi:10.1186/1755-8794-6-S3-S11

Cite this article as: Wang et al.: Correction: A comparison of statistical methods for the detection of hepatocellular carcinoma based on serum biomarkers and clinical variables. BMC Medical Genomics 2013 6(Suppl 3): S11.

\section{Submit your next manuscript to BioMed Central and take full advantage of:}

- Convenient online submission

- Thorough peer review

- No space constraints or color figure charges

- Immediate publication on acceptance

- Inclusion in PubMed, CAS, Scopus and Google Scholar

- Research which is freely available for redistribution
C Biomed Central 